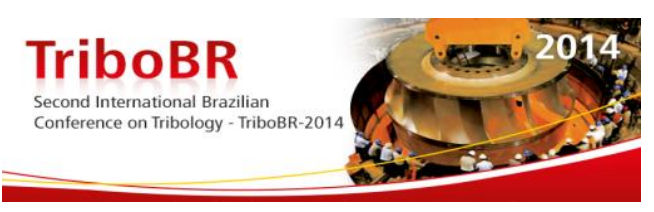

\title{
HIGH TEMPERATURE/VELOCITY EROSION OF THERMAL BARRIER COATINGS: FIELD DIAGNOSIS AND LABORATORY TESTING APPROACH*
}

\author{
Augusto César Barrios Tamayo \\ Luis Emilio Tobón Botero ${ }^{1}$ \\ Pablo Andrés Gómez Florez ${ }^{2}$ \\ Alejandro Toro ${ }^{3}$
}

\begin{abstract}
The high temperature erosion of Thermal Barrier Coatings (TBCs) is one of the main factors that define the lifespan in gas turbine components as it is considered the second source of failure of hot path components in power and propulsion turbine operation. The worn Top Coat (TC) surface in components such as first stage turbine blades affects the turbine efficiency due to energy losses and the increment in heat transfer to substrate. The first part of this work consists in describing a HTE test facility developed to emulate the damage conditions found in a number of components of gas turbines; in this testing machine, the samples were exposed to combustion gases moving at velocities close to $1.5 \mathrm{Mach}$ and temperatures of $1100^{\circ} \mathrm{C}$. The second part consists in the characterization of liners and first stage turbine blades of a GE7FA gas turbine used for power generation. The last part deal whit correlation of the features of TC's worn surfaces with the erosion conditions and the dominant degradation mechanisms between test samples and turbine components were compared.
\end{abstract}

Keywords: TBC; High temperature erosion; Turbine blade; Erosion testing facility; Turbine inspection; TMF; CTE.

1 M.Sc. Materials Engineering, Researcher, Tribology and Surfaces Group, Department of Materials and Minerals, National University of Colombia, Medellín, Colombia.

2 Ph.D. Materials Engineering, Chief engineer, La Sierra Thermoelectric plant, EPM, Colombia.

3 Ph.D., Associate Professor, Tribology and Surfaces Group, Department of Materials and Minerals, National University of Colombia, Medellín, Colombia.

* Technical contribution to the $2^{\text {nd }}$ International Brazilian Conference on Tribology - TriboBR 2014, November $3^{\text {rd }}$ to $5^{\text {th }}$, 2014, Foz do Iguaçu, PR, Brazil 


\section{INTRODUCTION}

Thermal Barrier Coatings (TBCs) are key factors in order to increase efficiency and satisfy environmental requirements in propulsion and power generation. In fact, the TBCs allow the increase of Turbine Entry Temperature TET and they are used also as a thermo-mechanical protecting layer in turbine hot path components such as combustion chambers and rotor/stator turbine blades [1,2]. In this context, erosion is considered the second cause of failure in power and propulsion gas turbine operation; this factor limits the lifetime of turbine hot path components [3,4]. The Plasma Sprayed TBCs (PS-TBCs) still keep good reliability/cost ratio respect to Electron Beam Physical Vapor Deposition TBCs (EB-PVD-TBCs). PS-TBCs are widely used in land based turbines and their high-temperature erosion resistance has been studied for many years, although there are many limitations for laboratory studies such as reproducing temperatures close to $1200^{\circ} \mathrm{C}$ and supersonic flow velocities $[5,6]$..

Recently, High Temperature Erosion (HTE) and Solid Particle Erosion (SPE) testing facilities have become popular around the world in accordance with industry developments. Companies and universities are implementing testing machines in order to determine the thermo-mechanical behavior of TBCs and high temperature materials $[4,7,8]$. Accordingly, this paper examines the erosion behavior of PS-TBCs samples exposed to HTE emulating the turbine operation regimes and the results of laboratory tests are correlated with the failure modes in first stage turbine blades and combustion liners.

\subsection{Classical Erosion Mechanisms in SPE and HTE}

The elastic Hertzian contact and median/lateral cracking in brittle materials have been used in order to explain the erosion mechanisms in TBC systems [3,9] despite the fact that relevant data such as localized superficial temperatures on the TC and impact velocities profiles near the surface and localized microstructural damages are very difficult to obtain. Previous works has been insisted in the knowledge of high temperature erosion mechanisms are only possible if well-controlled experiments are performed in test facilities capable to replicate the conditions expected in thermal machines such as turbine engines $[6,10]$.

Hertzian contact theory was developed under the premise of total elastic contact between two bodies; it is useful for explaining the impact contact in a wide range of materials, including brittle materials. It is important to annotate that the particle geometry has its effect: blunt erodent particles, low kinetic impact energy, high particle hardness and high impact angles collaborate to accomplish this regime [11,12]. The material removal depends on crack networks until it comes to surface, this is associated with fatigue. The impact stress distributions and their critical magnitude develop a cone crack, but in anisotropic materials like PS-TBC, the microstructure governing the crack propagation and its geometry dictates the way that the cracks propagate. Hertzian stress fields generate cracks under critical values, characteristic of each material's microstructure, these stresses distribute across the interfaces of the splats and in interfaces of columnar crystals in a TC.

The erosion phenomenon involves high impact energies involving sharp, hardened particles with high toughness, so the median-lateral cracking dominates the erosion scenario in brittle materials including a wide range of ceramics $[13,14]$. In this regime the critical radius of the impacting particles and the velocity of indentation define the

* Technical contribution to the $2^{\text {nd }}$ International Brazilian Conference on Tribology - TriboBR 2014, November $3^{\text {rd }}$ to $5^{\text {th }}, 2014$, Foz do Iguaçu, PR, Brazil 
crack nucleation and propagation. The irreversible generation of new surfaces occurs and lateral and median cracks are developed in a sequence determined by Lawn in 1975 and worked more extensively by Evans in 1976 [13,15. These events also occur in PS-TBCs but splat structure and its geometry modify where cracks grow and propagate depending on position of impact: normal or transversal to the TC.

A number of modern approaches to HTE rely on fluid mechanics and material mechanics coupling [16-19]. This point of view considers (for power generation turbines) the exclusive effect of fluid on wear of TC surface, the impact energy frequency is not associated to solid particles but it is related to shock waves and its frequencies, velocity fields and temperature gradients across the surface [16]. Also, the material response explains crack propagation in terms of plastic deformation, creep and sintering effects. In general, creep behavior of the top coat is strongly dependent on grain size and interlamelar sliding in APS coatings, while the direction of applied stresses on the coatings also plays an important role in the steady-state creep rates [16]. The onset of failure in TBCs may consequently be viewed as a competition between strain energy driven interfacial BC/TC crack growth mechanism and buckling induced instability and delamination. TGO has its participation in erosion wear because it debilitates the TC in order to resist fluid impacts. In this case the fracture mechanics approach says that sintering, TGO and accumulated stresses change stress intensity factor and fracture toughness of the TC [20,21].

So far, Full coupled elastic-plastic thermodynamic approach could be used to estimate the potential energy available in the system for a crack extension. A thermodynamically consistent framework for description of elasto(visco)-plasticity coupled with damage meets two general questions: the first one, is how to include damage to the Helmholtz free energy or the Gibbs thermodynamic potential (state coupling), and the second, how to couple dissipation potentials with damage in TBC systems (dissipation coupling) [16].

The erosion mechanisms of PS-TBC's have been correlated with splat removal and crack propagation across the inter-splat and trans-splat limits due to particle impact and impingement. Some works tried to approach erosion rates with grain boundaries in polycrystalline ceramics, in which the particle impact energies are released into the limits of the grains causing their removal [22,23]. Other approaches were developed specifically for PS-TBCs, with a similar premise: the particle impact energy is absorbed in splat boundaries causing the complete splat removal [24]. Both models explained some erosion mechanisms in PS-TBCs. Besides porosity and inter-splat contact, the internal microstructure of the splat plays a role in the TC erosion mechanisms. The splat has columnar crystals that generate columnar cracks perpendicular to inter-splat contact. These columns are formed during quenching, immediately after the splats were deposited [26,27]. Columnar crystals form internal splat microstructures. The splats can be removed from surface in several steps under successive gas impact. The columnar cracks propagate across the splat forming intra-splat cracks, when a piece of the splat is removed and the inter-plats cracks can be observed.

There are three types of fractures observed in a splat structure, see figure 1: (I) Intrasplat: lateral cracks formed between two splats, perpendicular to surface. (ii) Transsplat: cracks formed across the splat since its deposition, which propagate perpendicular to surface. (iii) Inter-splat: cracks formed between the splats deposited from top to bottom, they are also called inter-splat pores and are associated with inter-splat contact area in some erosion studies.

* Technical contribution to the $2^{\text {nd }}$ International Brazilian Conference on Tribology - TriboBR 2014, November $3^{\text {rd }}$ to $5^{\text {th }}$, 2014, Foz do Iguaçu, PR, Brazil 

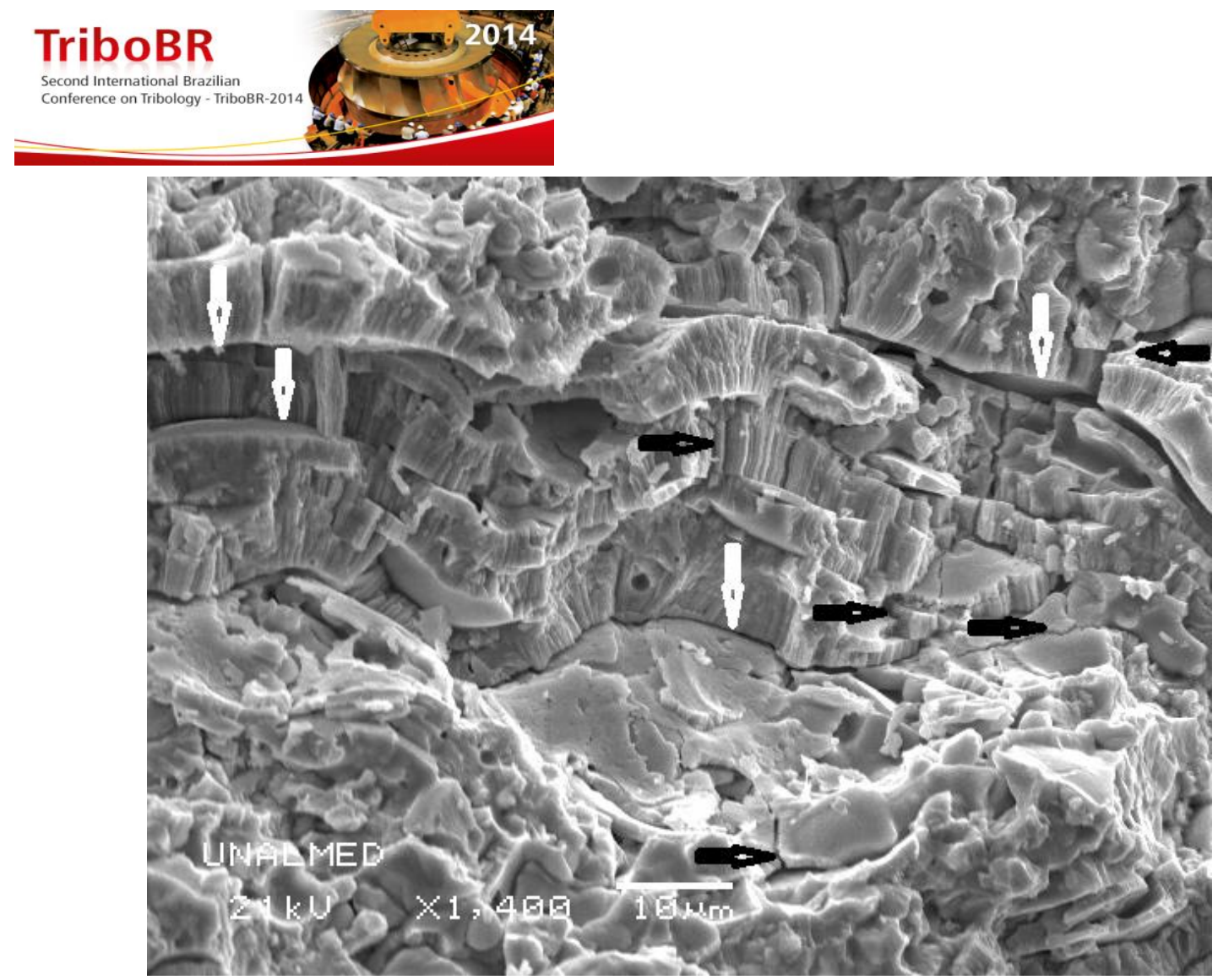

Figure 1. Splat type microstructure of PS-TC. White arrows indicate inter-splat cracks, black arrows to the right indicate columnar cracks (trans-splat) and black arrow to the left indicate intra-splat crack.

This work proposes an erosion characterization methodology for PS-TBC surfaces submitted to the impact of a transonic/supersonic combustion gas stream. Characterization of the surfaces is accompanied by the analysis of the microstructure changes in TC surface in order to determine the dominant erosion mechanisms.

\section{MATERIALS AND METHODS}

Three kinds of samples were examined: as-sprayed TBC coupons, liner samples and first stage turbine blades samples. The coupons were erosion tested and characterized in order to compare their behavior with those of real turbine components. All the samples were standard porous PS-TBCs with classical four-layer structure: Inconel 625 substrate, $\mathrm{M}(\mathrm{Ni}, \mathrm{Mo})$ CrAlY Bond Coat $(\mathrm{BC}), 7 \% \mathrm{Y}_{2} \mathrm{O}$ doped $\mathrm{ZrO}_{2}$ Top Coat (TC) deposited through air plasma spray (APS) process and Thermally Grown Oxide TGO

The liner and first stage blades are components of a GE7FA gas turbine. The liner was sectioned in seven levels from the transition piece to the burner coupling in order to study the variations in the topography of the worn surfaces. Each liner's section is an annular piece from which rectangular samples were extracted by using a Buehler Isomet ${ }^{\circledR} 5000$ cutting machine operating at $4000 \mathrm{rpm}$ and $1.2 \mathrm{~mm} / \mathrm{min}$ feed-rate. The rectangles were subdivided into four surface areas that represent the quadrants of the Cartesian plane. The representative worn areas were selected and cleaned in order to be characterized using Optical Stereo Microscope (OSM) and Scanning Electron Microscope (SEM). The first stage turbine blades were prepared and observed with OSM on suction and compression sides. Their characterized areas include stagnation point, trailing edge and leading edge. The sample surfaces were observed in five points (including stagnation point) according to rectangular coordinates using OSM in order to track the texture evolution during erosion tests. SEM was used to take TCs top and cross-sectional views. The pictures were

* Technical contribution to the $2^{\text {nd }}$ International Brazilian Conference on Tribology - TriboBR 2014, November $3^{\text {rd }}$ to $5^{\text {th }}$, 2014, Foz do Iguaçu, PR, Brazil 


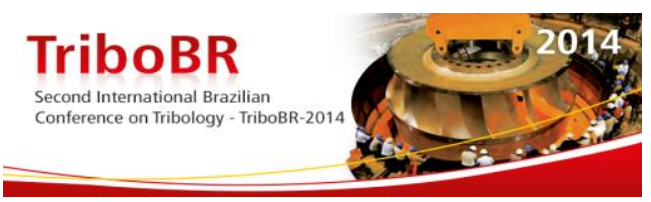

processed and analyzed with NIKON NIS Elements software in order to identify particles, degradation of the splats, fractures and erosion mechanisms on worn surfaces.

For transversal characterization of eroded TC the samples were processed in resin: the metallographic preparation was performed by grinding the samples on emery papers n. 400 and 600 for 5 minutes followed for polishing in clothes Ultrapath ${ }^{\circledR}$, Texmet $^{\circledR}$ and Microcloth ${ }^{\circledR}$ with abrasive polycrystalline diamond suspension of $12 \mu \mathrm{m}$, $6 \mu \mathrm{m}, 3 \mu \mathrm{m}$ and $1 \mu \mathrm{m}$. The final polishing was performed with 0.06 Silica suspension. The erosion tests of as-sprayed TBC coupons were performed in a home-built testing device whose constructive details and specifications are described in section 3.1. The samples were exposed to combustion gases at $1200^{\circ} \mathrm{C}$ varying the impact angles during 4 hours. The temperature variations of the eroded surface and the cooled substrate were monitored during the tests. The samples were characterized in order to elucidate the material removal mechanisms. The results were correlated with erosion in real turbine components as a liners and first stage blades.

\section{RESULTS AND DISCUSSION}

\subsection{High Temperature Erosion Testing Facility}

A high temperature erosion testing facility was developed in order to perform erosion tests under conditions similar to those of turbine operation. This device has the capability of reaching gas velocities near 1.5 Mach and gas temperatures until $1200^{\circ} \mathrm{C}$. These erosion conditions are similar to those found in first stage turbine blades, liners and transition pieces.

This device has the capability for varying the average impingement angles of the gases between $0^{\circ}$ and $90^{\circ}$, the sample distance from the nozzle and the average gas velocity.

A sketch of the testing facility is shown in figure 1. The device is composed by $(A)$ gas combustor, (B) combustion chamber, (C) Laval nozzle, (D) test sample holder and $(E)$ exhaust gases. The temperature cycle is programmed in the PID controller, the ignition and the combustion cycle rely on the combustion controller $(A)$ and throughout the test the stoichiometric controller ensures the optimal gas/air ratio. The combustion gases are directed from the combustion chamber $(B)$ to the Laval nozzle (C) in order to be accelerated to supersonic regime. Then, the combustion gases impact the sample attached in the sample holder at speed of $1.5 \mathrm{Mach}$. The calculated test conditions for HTE test facility are shown in table 1.

Table 1. Test conditions for HTE test facility.

\begin{tabular}{|l|l|l|}
\hline Operation Variables & Test condition 1 & Test condition 2 \\
\hline Temperature (K) & 1323.15 & 1073.15 \\
\hline Fluid velocity (Mach) & $0.3-0.4$ & $1.5-2$ \\
\hline Dinamic pressure (MPa) & 0.037 & 1.6 \\
\hline
\end{tabular}

During the tests the temperature on the TBC surface, in the combustion chamber and immediately above the nozzle exit are monitored in order to calculate the gas flow velocity. 

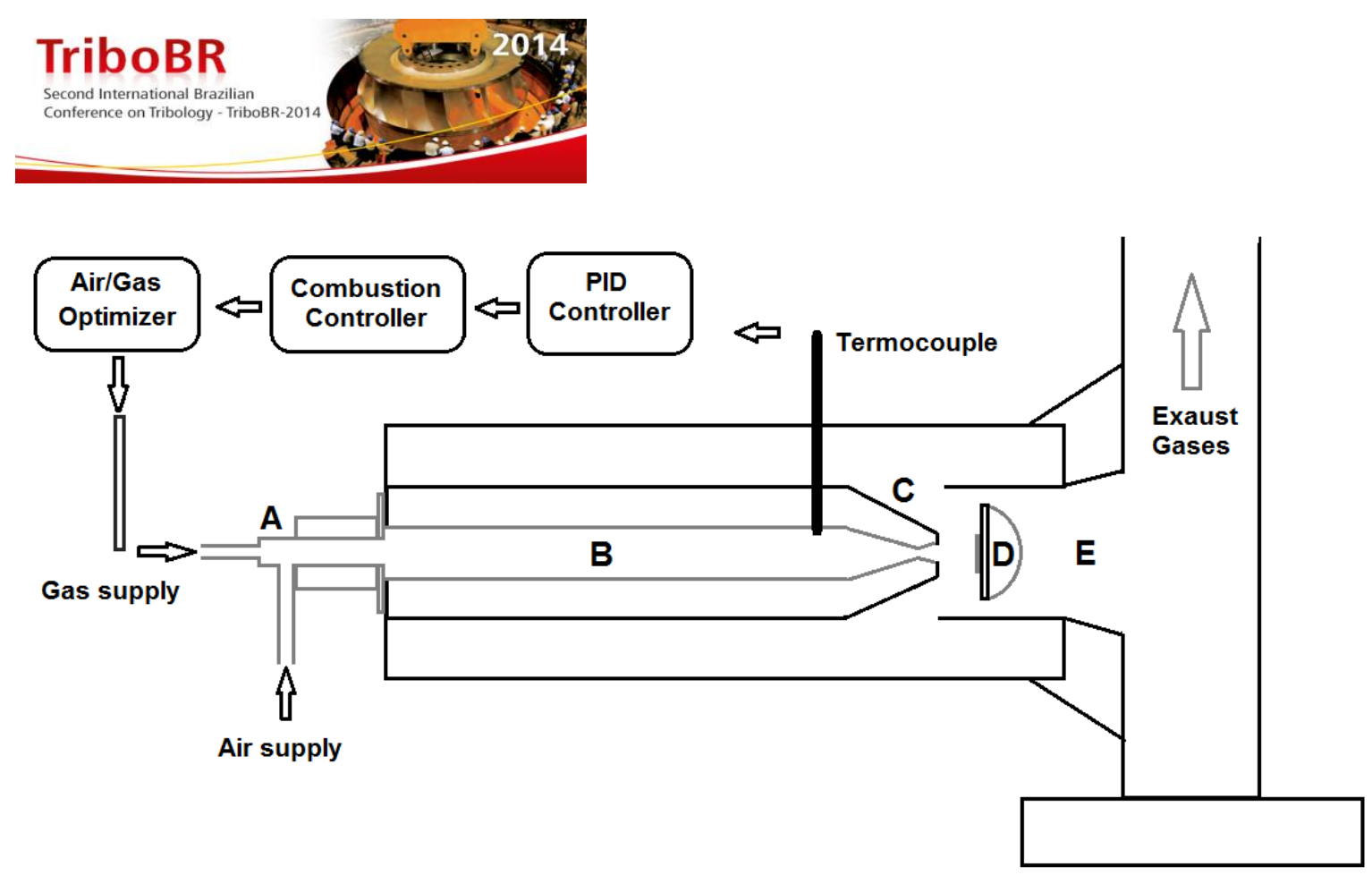

Figure 1. Schematic of HTE testing facility

The erosion tests were performed at average impact angle of $90^{\circ}$. The supersonic regime was established as it was confirmed by the formation of the Prandlt expansion cone shown in figure 2. In the figure, the light is emitted because of the presence of air moisture in the combustion gases. The main worn area was near the stagnation point.

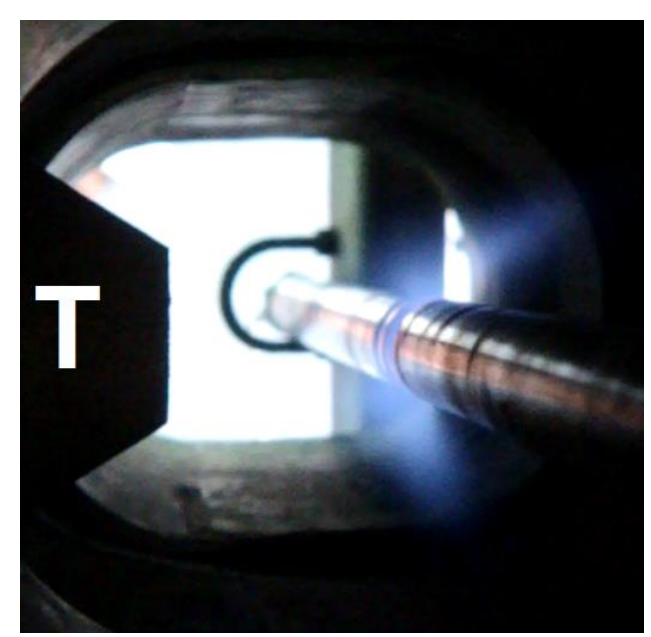

Figure 2. Prandlt expansion cone, typical of gases in supersonic regime. $\mathrm{T}$ is the Laval Nozzle. Combustion gases impacted the sample at average angle of $90^{\circ}$.

a. Erosion mechanisms: The worn surfaces of test samples revealed splat removal in the TC and the main damage mechanisms identified were fatigue and brittle fracture. Figure 3 shows the TC surface texture obtained after 4 hours of erosion testing. 

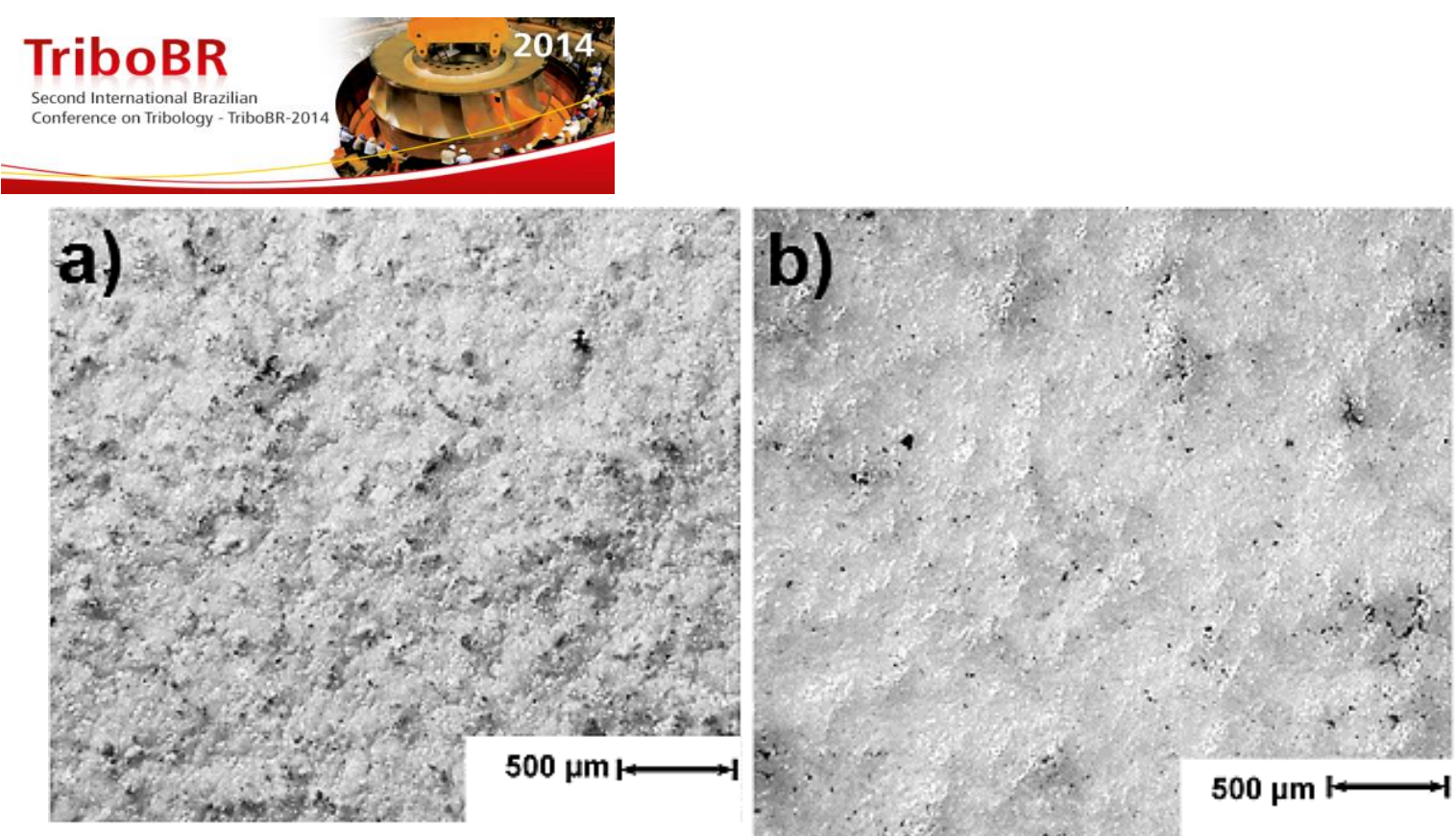

Figure 3. a) As-deposited PS-TBC test sample y b) the same sample after 4 hours of erosion testing at $90^{\circ}$ average impact angle, $1100^{\circ} \mathrm{C}$ and average velocity of 1.2 Mach. Stagnation point.

Figure 4 shows evidences of trans-columnar crack propagation across the splats. Presence of such trans-splat cracks promotes a progressive splat removal process by fatigue and brittle fracture that leads to partial or total detachment of material. The well-deposited splats presented this type of progressive damage, while thicker splats tend to be removed completely via inter-splat contact.

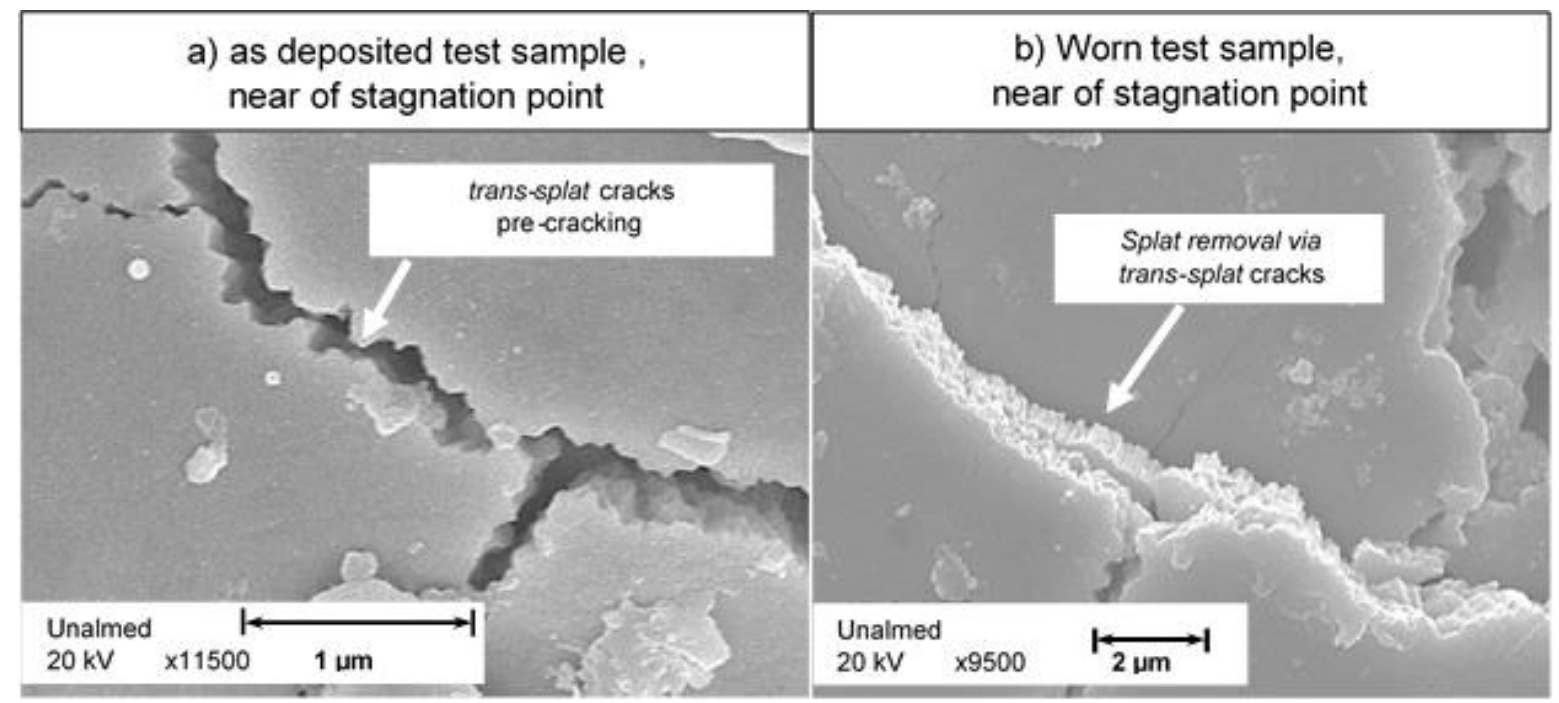

Figure 4. The TC wear involved trans-columnar crack propagation, this test sample was impacted with average angle of $90^{\circ}$, velocity of 1.2 Mach and $1100^{\circ} \mathrm{C}$. a) Splat surface of the PS-TC before the erosion test, it is composed for pre-cracks and, b) Same splat after erosion test.

In the samples extracted from the liner the basic damaging mechanisms of the TC were found, i.e., Inter-splat, intra-splat and trans-splat crack propagation, as shown in Figure 5. 

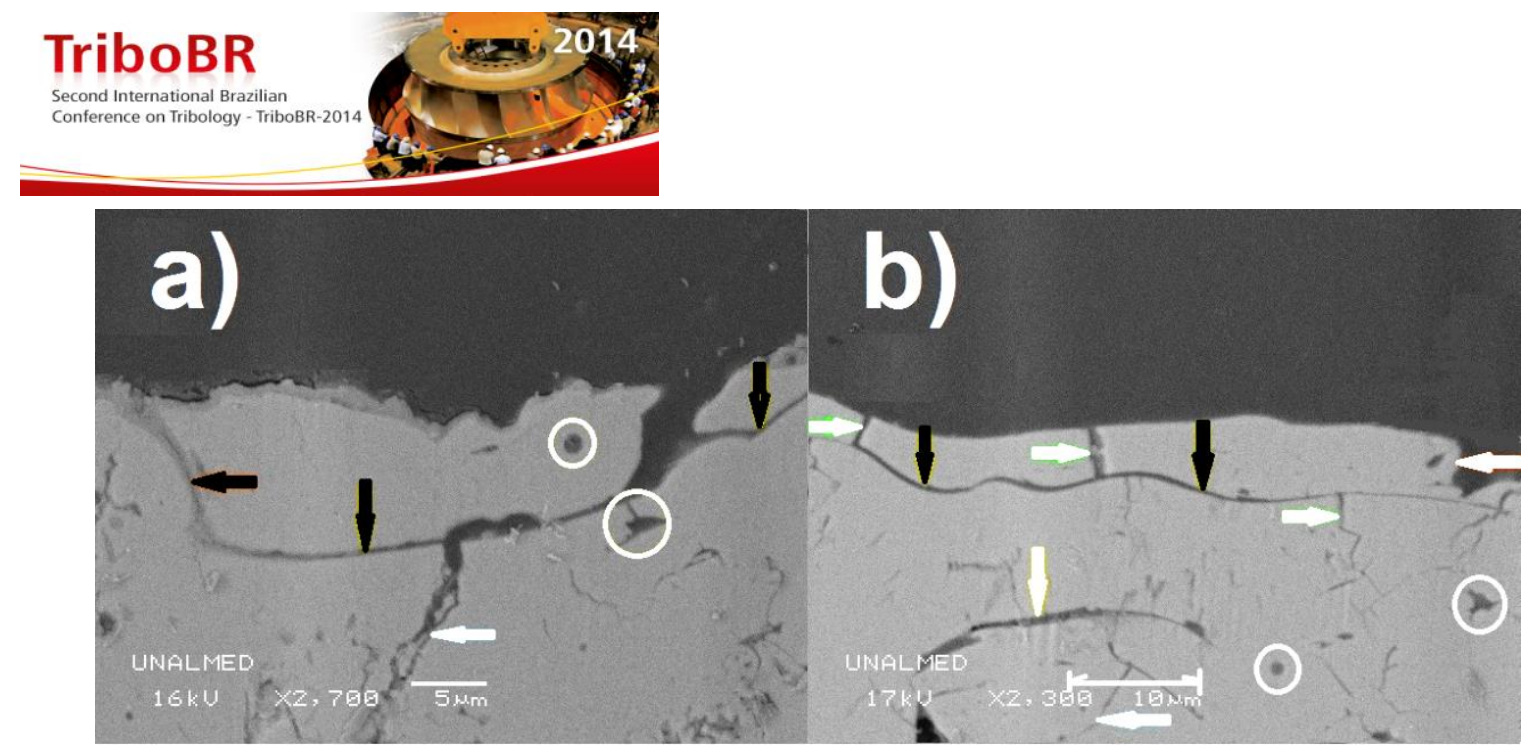

Figure 5. Cross sectional samples of a liner with 8400 hours a) cracks propagate across intersplats contact in a thick lamella b) trans-columnar fracture in a well deposited lamella. Trans-lamellar cracks (black arrows), intra-lamellar cracks (white arrows to the left), inter-lamellar cracks (white arrows to the right) and pores (white circles).

Inter-splat cracking involves detachment of complete un-melted particles and thick splats, intra-splat cracking relates to progressive splat removal and it occurs mainly in thin, well deposited splats with more inter-splat contact area than the thicker splats. Although it is difficult to determine when a deposited un-melted particle becomes a splat in the TC, the following data show that thick un-melted particles/splats tend to be removed completely: the average diameter of thick splats (which could be unmelted particles) were $111 \pm 47 \mu \mathrm{m}$ while the cavities as a result of splat/un-melted particles detachment had an average diameter of $184 \pm 81 \mu \mathrm{m}$, this size was greater than the average diameter of splats, which is consistent with the complete removal of splats or un-melted particles. The dispersion of values was due to the anisotropy of the TC. On the other hand, in cross-sectional pictures of the TC in as-sprayed test samples, thin lamellae with average thickness $6 \pm 1.8 \mu \mathrm{m}$ (maximum value $10 \mu \mathrm{m}$ and minimum value $1.56 \mu \mathrm{m}$ ) tend to be removed in several stages. Thick lamellae had $14.5 \pm 1.8 \mu \mathrm{m}$ average thickness with a maximum value of $31.21 \mu \mathrm{m}$ and minimum value of $10 \mu \mathrm{m}$ and they tend to be removed completely in worn test samples. As-sprayed test samples were compared with samples extracted from the worn liner in order to study the effect of splat trans-columnar pre-cracks in removal mechanisms. It was found that the mass removal proceeded via columnar grain interfaces.

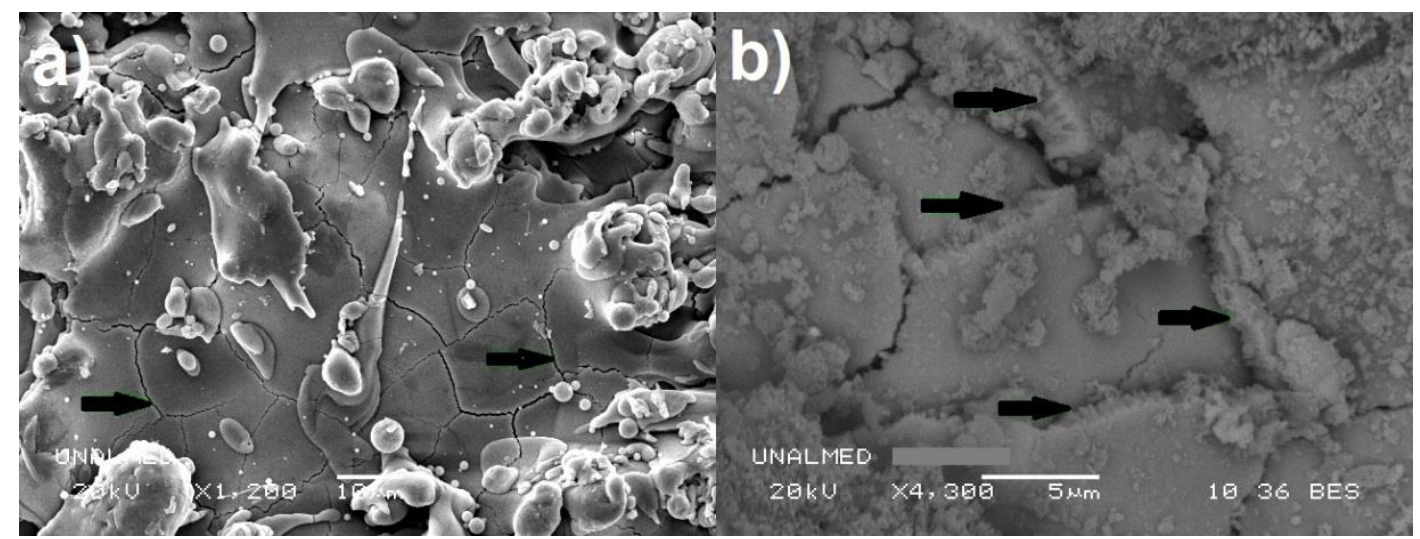

Figure 6. Comparison between as-sprayed test sample before the erosion tests and Liner with 8400 hours of service. a) Pre-cracks across the splat formed during rapid cooling after deposition they are known as intra-splat cracks (black arrows). b) During operation these cracks propagate in order to detach a piece or pieces of the splat. Arrows indicates pre-cracking and columnar fracture in a splat (black arrows).

* Technical contribution to the $2^{\text {nd }}$ International Brazilian Conference on Tribology - TriboBR 2014, November $3^{\text {rd }}$ to $5^{\text {th }}$, 2014, Foz do Iguaçu, PR, Brazil 


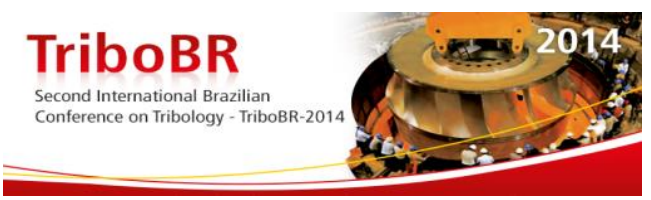

\subsection{Turbine Blade}

In the case of the turbine blade, identifying the erosion mechanisms was more difficult due to the occurrence of other events such as delamination and spallation caused by differences in CTE (Coefficient of Thermal Expansion). TC mass removal via splats happened specifically in trailing edge and leading edge of the turbine blade near the tip. Figure 7 shows the leading edge with cracks due to blade expansion caused by high centrifugal forces (associated to $3600 \mathrm{rpm}$ in base load and temperatures near to $1200^{\circ} \mathrm{C}$ ). The surface in mid span compression side presented cracks associated to substrate crack propagation between crystals with directional growth due to thermal mismatch and diffusional phenomenon. The same situation but with different average impact angles was observed in trailing edge, it involved gradual TC wear with splat removal similar to what was observed in the samples tested in HTE test facility.

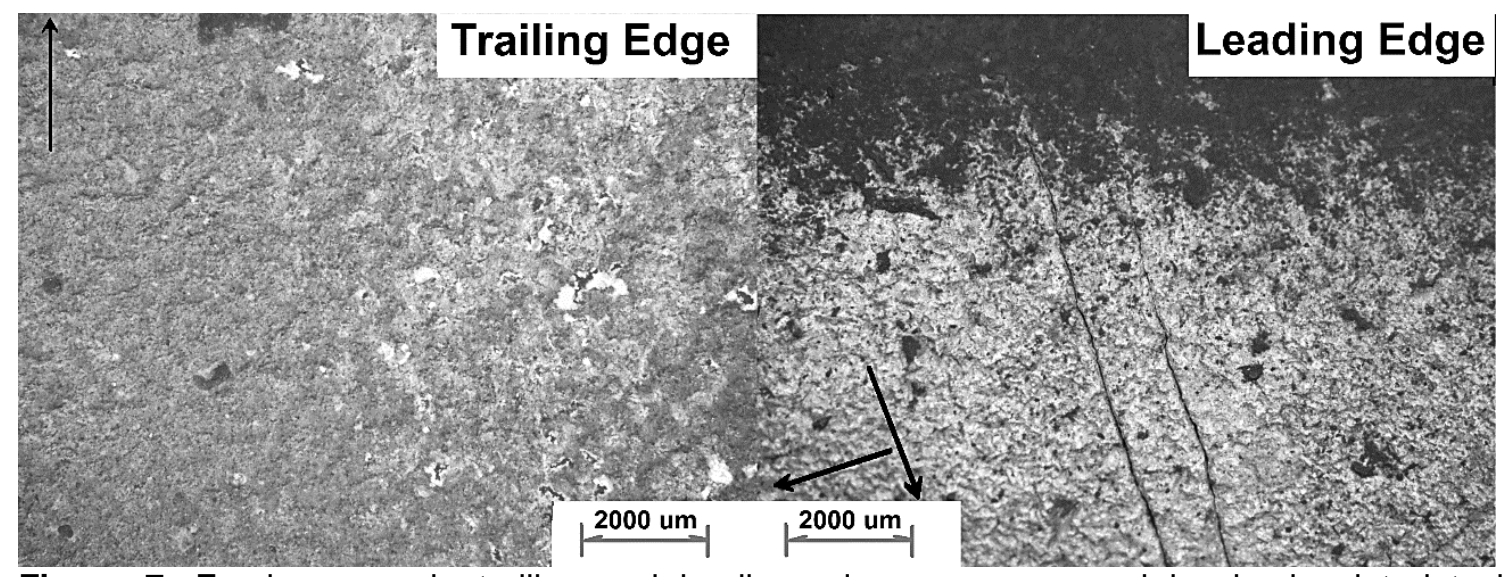

Figure 7. Erosion wear in trailing and leading edge, mass removal involved splat detachment represented in gradual TC detachment. The arrows indicate the average direction of combustion gases. The arrow perpendicular to the other one indicates the direction of centrifugal forces.

\subsection{Liner}

Liner worn surfaces presented splat detachment showed in lighter areas of figures 8 a) and 8 b) where combustion gases impacted the TC until came to transition piece.

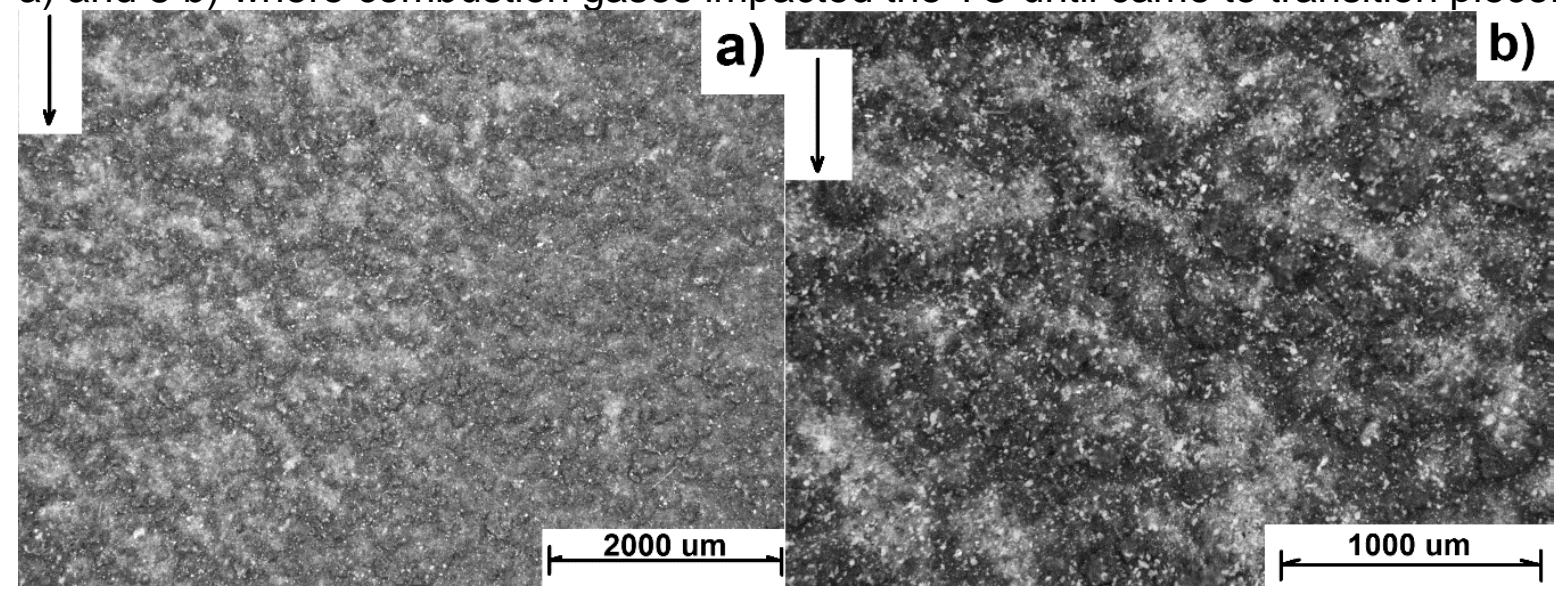

Figure 8. Worn surfaces of liner a) combustion gases impacted the TC area in the left (lighter areas) and, b) detailed area of worn TC surface of liner that involved splat detachment.

A closer view about topography of worn surfaces in liner and the test sample is shown in figure 9, the inter-splat cavities in the TC surface are related to splat

* Technical contribution to the $2^{\text {nd }}$ International Brazilian Conference on Tribology - TriboBR 2014, November $3^{\text {rd }}$ to $5^{\text {th }}$, 2014, Foz do Iguaçu, PR, Brazil 


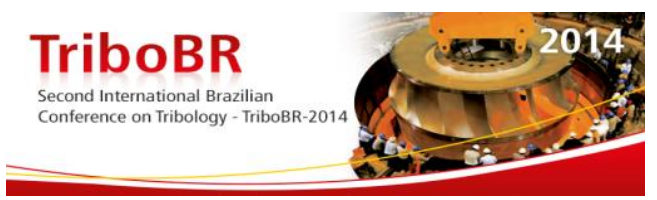

detachment and both intra and inter-splat cracks. Mass removal in test and liner surfaces indicates inter splat chipping increasing the undulation of the sample but not necessary roughness.

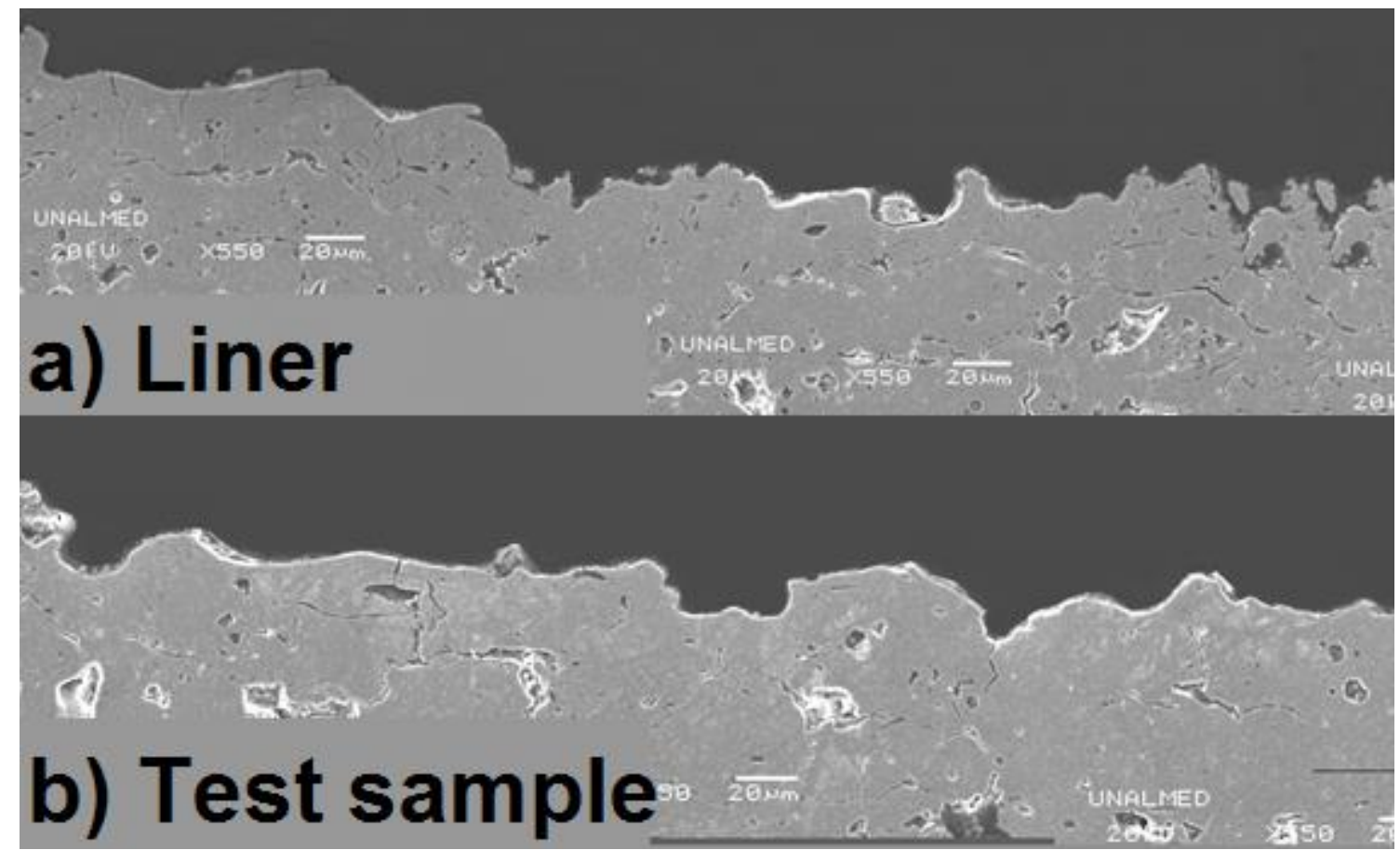

Figure 9. Comparison of cross-sectional microstructures of liner with 8000 hours of service and sample tested in laboratory.

When the Power Spectral Density (PSD) was analyzed from profiles of new and worn test samples, figure 10; it was confirmed that some of the wavelengths associated to roughness disappeared and the influence of waviness on the main features of the surface is greater.

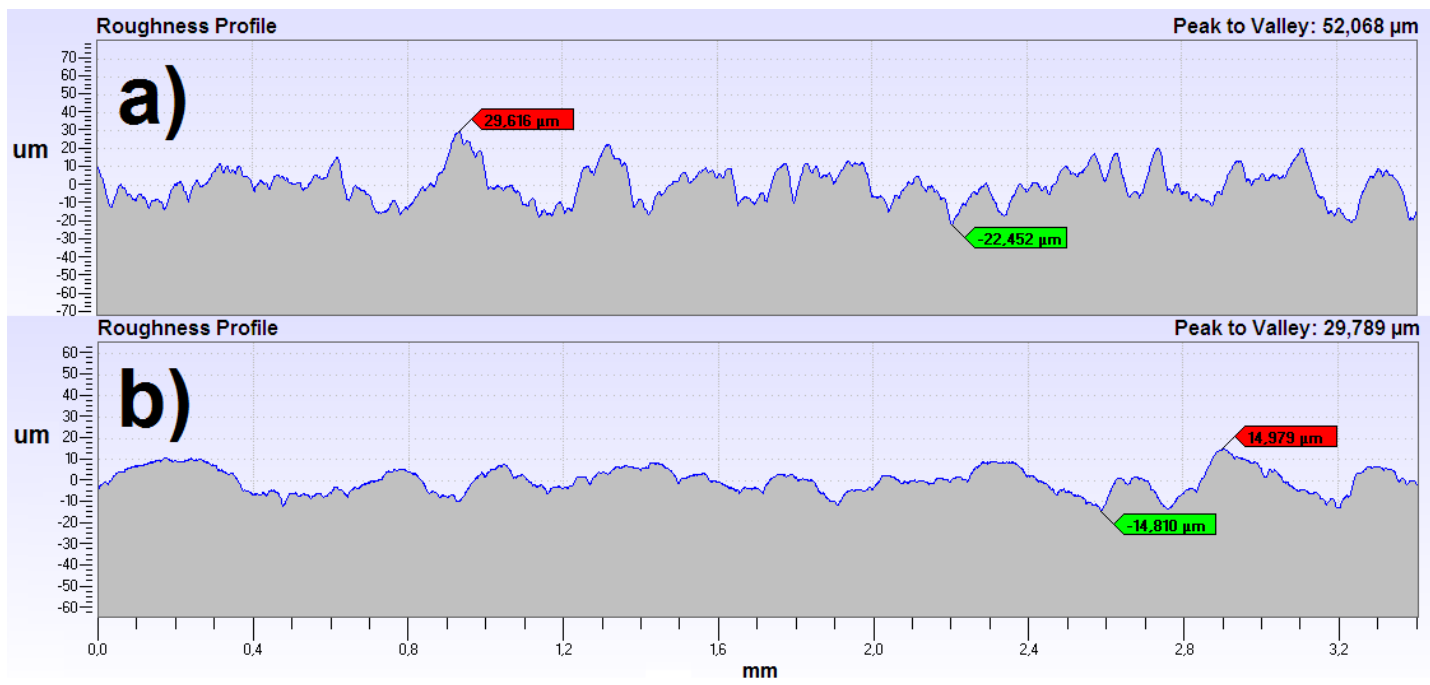

Figure 10. Profiles of a) new test sample with main components associated to roughness and waviness

* Technical contribution to the $2^{\text {nd }}$ International Brazilian Conference on Tribology - TriboBR 2014, November $3^{\text {rd }}$ to $5^{\text {th }}$, 2014, Foz do Iguaçu, PR, Brazil 


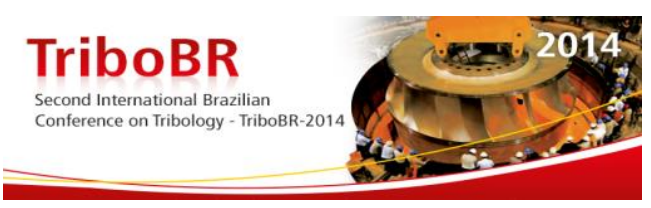

When PSD and spatial measurements of the TC were correlated some groups of characteristic frequencies were identified as follows (see figure 11):

- The shape of the liner is associated to frequencies between 0 to $0.2 \mathrm{~mm}^{-1}$ corresponding to characteristic wavelengths $\lambda$ between 10 and $5 \mathrm{~mm}$.

- Waviness: corresponds to frequencies between 0.2 and $1.3 \mathrm{~mm}^{-1} ; \lambda=5$ $\mathrm{mm}$ to $800 \mu \mathrm{m}$, these distances were related to plasma spray path or furrows, they also correspond to BC furrows. Characteristic frequencies $\mathrm{CF}=0.3$ to $1.2 \mathrm{~mm}^{-1}$

- So-called waviness-roughness "gray zone": waviness associated to groups of splats is on the same order of magnitude than roughness associated to individual splats, $1.3 \mathrm{~mm}^{-1}$ to $2.2 \mathrm{~mm}^{-1} ; \lambda=800 \mu \mathrm{m}$ to $450 \mu \mathrm{m} ; C F=1.5$ to $1.8 \mathrm{~mm}^{-1}$.

- Roughness: $2.2 \mathrm{~mm}^{-1}$ to $10 \mathrm{~mm}^{-1} ; \lambda=450 \mu \mathrm{m}$ to $100 \mu \mathrm{m}$, It corresponds

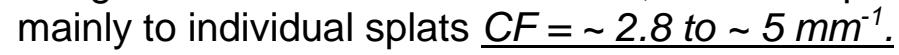

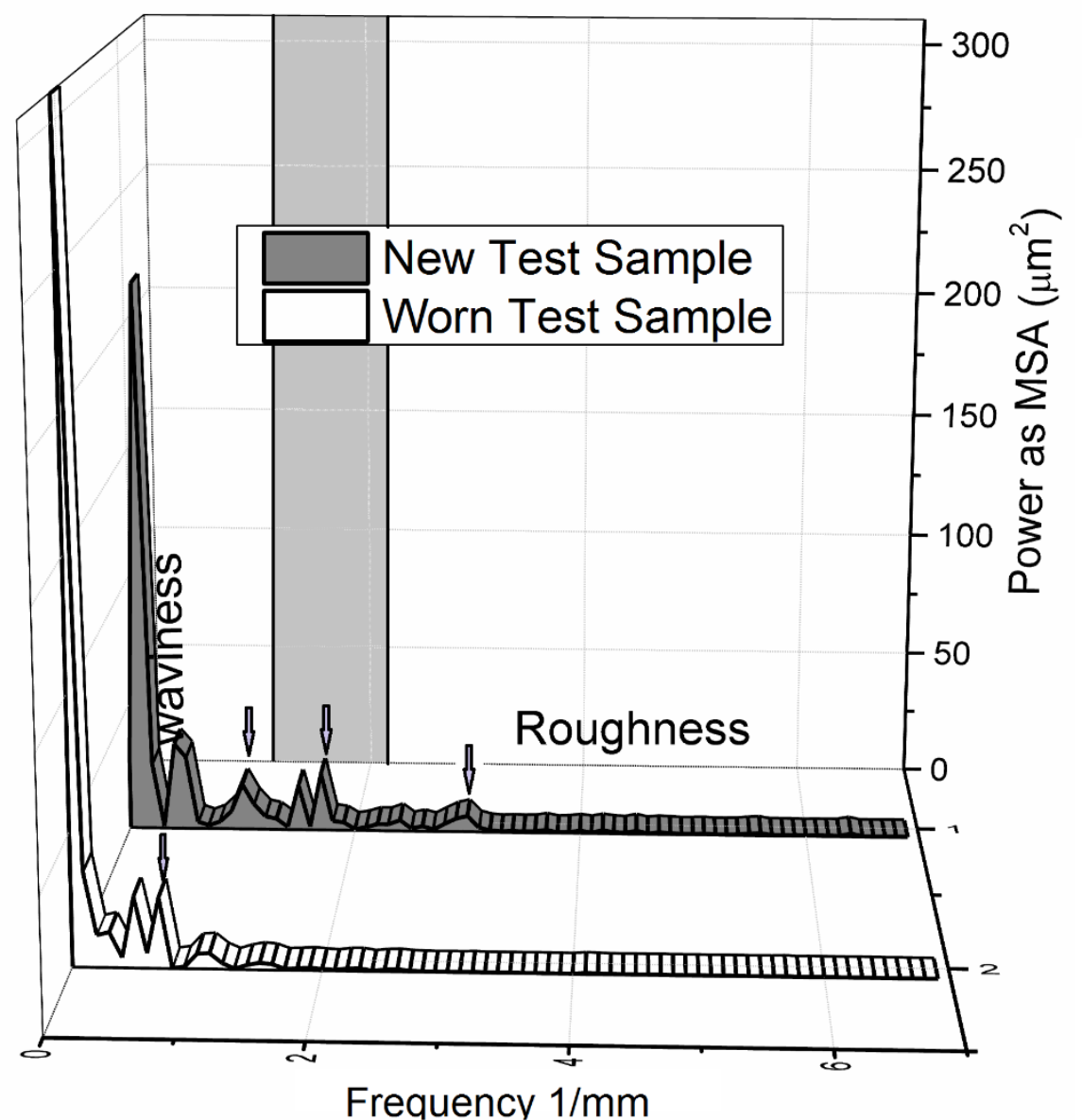

Figure 11. PSD of TC surface: i) test sample reference, ii) worn TC surface. Shape factor: power at frequencies from 0 to $0.2 \mathrm{~mm}^{-1}$, distance, $\lambda=10$ to $5 \mathrm{~mm}$; waviness: 0.2 to $1.3 \mathrm{~mm}^{-1}$ corresponding to $\lambda=5 \mathrm{~mm}$ to $770 \mu \mathrm{m}$; transition zone between waviness and roughness: $1.3 \mathrm{~mm}^{-1} \mathrm{a} 2.2 \mathrm{~mm}^{-1}, \lambda=800$ $\mu \mathrm{m}$ to $450 \mu \mathrm{m}$; roughness: $2.2 \mathrm{~mm}^{-1}$ to $10 \mathrm{~mm}^{-1}, \lambda=450 \mu \mathrm{m}$ a $100 \mu \mathrm{m}$.

Erosion causes an increase in the predominance of waviness while it reduces $\mathrm{Ra}$ from 7,84 $\pm 1.33 \mu \mathrm{m}$ to $4.43 \pm 0.45 \mu \mathrm{m}$. Specific frequencies in PSD show that the power in $0.5 \mathrm{~mm}^{-1}$ was reduced but other peak in proportion 1:1 with this peak appeared in $0.8 \mathrm{~mm}^{-1}$. Power in $1.2 \mathrm{~mm}^{-1}$ associated to groups of splats was reduced and then two peaks of roughness appeared at 1.6 and $1.8 \mathrm{~mm}^{-1}$.

* Technical contribution to the $2^{\text {nd }}$ International Brazilian Conference on Tribology - TriboBR 2014, November $3^{\text {rd }}$ to $5^{\text {th }}$, 2014, Foz do Iguaçu, PR, Brazil 


\section{CONCLUSIONS}

The erosion test equipment developed offers an evaluation of HTE in TBCs that includes the main effect of combustion gases with low concentration of solid particles.

The erosion tests reproduced the erosion media conditions encountered in land based turbines with air filtered combustion gases: Supersonic gas flows, shock waves, temperatures up to $1200^{\circ} \mathrm{C}$ and low concentration of solid particles.

The obtained worn surfaces in test samples had similar erosion marks in relation to liner and first stage turbine blades. The mass removal was via splats detachment as expected and reported in previous works $[7,28]$. However, a different mechanism that involves intra columnar crack propagation across the columnar crystals of thin splats was also observed.

Deposition parameters must be directed in order to get well deposited splats in the TC. Splats with thicknesses inferior to $10 \mu \mathrm{m}$ could eventually reduce the mass loss in erosion because the splats are detached progressively, while splats with thicknesses up to 10 um tend to be removed completely.

\section{Acknowledgments}

The authors thank to Universidad Nacional de Colombia, Colciencias and Empresas Públicas de Medellín for financial funding and access to laboratories and facilities.

\section{REFERENCES}

1 Gurrappa I, Sambasiva RA. Thermal barrier coatings for enhanced efficiency of gas turbine engines, Surf. Coatings Technol., 2006; 201(6): 3016-3029.

2 Clarke DR, Levi CG. Materials design for the next generation, thermal barrier coatings," Annu. Rev. Mater. Res., 2003; 33(1): 383-417.

3 Wellman RG, Nicholls JR. A review of the erosion of thermal barrier coatings," J. Phys. D. Appl. Phys., 2007; 40(16): R293-R305.

4 Cernuschi F, Lorenzoni L, Capelli S, Guardamagna C, Karger M, Vaßen R, Von Niessen K, Markoscan N, Menuey J, Giolli C. Solid particle erosion of thermal spray and physical vapour deposition thermal barrier coatings, Wear; 2010,2011..

5 NASA, "NASA Thermal Barrier Coatings, Technical Memo Nro. 86905," in Advances in Aeronautical Materials, 1985.

6 Evans AG, Fleck NA, Faulhaber S, Vermaak N, Maloney M, Darolia R. Scaling laws governing the erosion and impact resistance of thermal barrier coatings," Wear, 2006; 260(7-8): 886-894.

7 C.-J. Li, G.-J. Yang, Ohmori A. Relationship between particle erosion and lamellar microstructure for plasma-sprayed alumina coatings, Wear, 2006; 260(11-12): 11661172.

8 Tabakoff, Shanov V. Erosion rate testing at high temperature for turbomachinery use, Surf. Coatings Technol., 1995; 76-77: 75-80.

9 Wellman R, Nicholls J. High temperature erosion-oxidation mechanisms, maps and models, Wear, 2004; 256(9-10): 907-917.

10 Cernuschi F, Lorenzoni L, Capelli S, Guardamagna C, Karger M, Vaßen R. Solid particle erosion of thermal spray and physical vapour deposition thermal barrier coatings, Wear, 2011; 271(11-12): 2909-2918.

11 Finnie I. Erosion by Solid Particles in a Fluid Stream, ASTM Int., 1962.

12 Hamed A, Tabakoff WC, Wenglarz RV. Erosion and Deposition in Turbomachinery, J. Propuls. Power, 2006, 22(2): 350-360. 


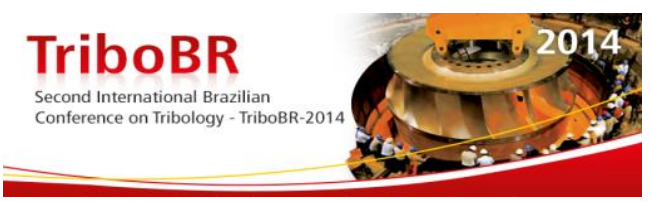

13 Lawn BR, M.V.Swain MV. Microfracture Beneath Point Indentations in Brittle Solids, J. Mater. Sci., 1975; 10: 113-122.

14 Evans AG, Chesnutt JC, Nadler H. Quasi-static solid particle in damage in brittle solid II. Indentation Friction, Acta Metall., vol. 24, pp. 867-870, 1976.

15 Spears MA, Evans AG. Microstructure development during final intermediate stage sintering II. Grain and pore coarsening, Acta Metall., 1982; 30: 1281-1289.

16 Gómez Flórez P. Analytical Model for High Temperature Wear in Thermal Barrier Coatings Under Non-Steady State Conditions In Gas Turbines, PhD Thesis, National University of Colombia, 2012.

17 Finnie I. Some reflections on the past and future of erosion, Wear, vol. 186-187, pp. 110, Jul. 1995.

18 Meng HC, Ludema KC. Wear models and predictive equations: their form and content, Wear, 1995; 183: 443-457.

19 Lyczkowski RW, J. X. Bouillard JX. State-of-the-art review of erosion modeling in fluid/solids systems, Prog. Energy Combust. Sci., 2002; 28(6): 543-602.

20 Osorio JD, Maya D, Barrios AC, Lopera A, Jiménez F, J. M. Meza JM, Ortiz JPH, Toro A. Effect of thermally grown oxide growth and microstructure changes on fracture toughness in air plasma sprayed thermal barrier coatings under heat treatment, Am. Ceram. Soc., 2013; Accepted M.

21 Osorio JD, Toro A, Hernández-Ortiz JP, Phase transformations in air plasma-sprayed yttria-stabilized zirconia thermal barrier coatings, DYNA, 2014; 3.

22 Ritter JE. Erosion damage in structural ceramics, Mater. Sci. Eng., 1985; 71: 195-201.

23 Ritter JE, Rosenfeld L, Jakus K. Erosion and strength degradation in alumina, Wear, 1986; 111(4): 335-346.

24 Li C-J, Arata Y, Ohmori A, Basic Studies on Plasma Ceramics Coatings. Report 1: Erosion mechanism at ACT-JP process," Trans. JWRI, 1986; 15(2).

25 Eaton HE, Novak RC, Particulate erosion of plasma-sprayed porous ceramic, Surf. Coat. Technol., 1987, 30: 41-50.

26 Haynes JA, Ferbe MK, Porter WD, Characterization of Alumina Scales Formed During Isothermal and Cyclic Oxidation of Plasma-Sprayed TBC Systems at $1150^{\circ} \mathrm{C}$, Oxid. Met., 1999; 52.

27 Portinha A, Teixeira V, Carneiro J, Martins J, Costa MF, Vassen R, Stoever D, Characterization of thermal barrier coatings with a gradient in porosity, Surf. Coatings Technol.; 195(2-3): 245-251.

28 Nicholls J, Deakin M, Rickerby D. A comparison between the erosion behaviour of thermal spray and electron beam physical vapour deposition thermal barrier coatings, Wear, 1999; 233-235: 352-361.

29 Shipway $\mathrm{PH}$, Hutchings IM. Measurement of coating durability by solid particle erosion, 1995; 71: 1-8.

* Technical contribution to the $2^{\text {nd }}$ International Brazilian Conference on Tribology - TriboBR 2014, November $3^{\text {rd }}$ to $5^{\text {th }}$, 2014, Foz do Iguaçu, PR, Brazil 